\title{
Materiais lúdico-educativos sobre as Mulheres Cientistas do Coronavírus e o alcance da Divulgação Científica
}

\author{
Ludic Educational Materials about Women \\ Scientists of Coronavirus and the scope of \\ Scientific Dissemination
}

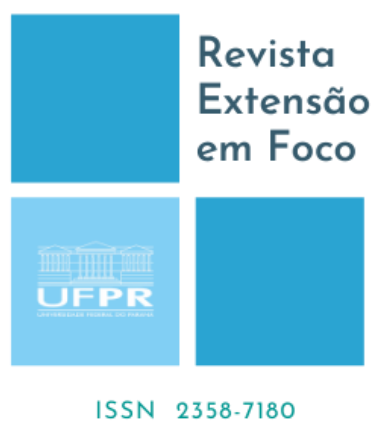

\author{
Camila Silveira ${ }^{1}$, Clarice Dias Britto do Amaral $^{2}$, Glaucia Pantano ${ }^{3}$, Alessandra Souza \\ Barbosa $^{4}$, Camilla Karla Brites Queiroz Martins de Oliveira ${ }^{5}$, Tatiana Renata Gomes \\ Simões ${ }^{6}$
}

\begin{abstract}
RESUMO
Neste artigo relatamos a experiência do Projeto de Extensão Meninas e Mulheres nas Ciências (MMC) da Universidade Federal do Paraná em divulgar informações técnico-científicas por meio de materiais lúdico-educativos sobre a Covid-19, na perspectiva da Divulgação Científica, para o grande público. Dentre as ações educativas do projeto, foi produzido um livro de passatempos em formato eletrônico contendo caça-palavras, palavras-cruzadas e desenhos para colorir que abordavam o trabalho das cientistas sobre o coronavírus e outros assuntos correlatos. Por meio de uma pesquisa social documental foram levantados dados sobre o alcance das atividades do Projeto, revelando o expressivo alcance do livro. Páginas de internet, sites e portais institucionais de sociedades científicas, museus de ciências e projetos temáticos compartilharam notícias sobre o lançamento do material; as professoras da equipe participaram (remotamente) de dezenas de eventos; diversos portais de notícias e entretenimento avultaram a publicação do livro e produziram matérias especiais sobre o trabalho do MMC em relação ao coronavírus. A Educação para o Desenvolvimento Sustentável, da Agenda 2030 da Organização das Nações Unidas, foi promovida por meio dos Objetivos de Aprendizagem para os ODS 3, 4, 5, 10 e 16. Os resultados obtidos destacam as potencialidades e o compromisso do projeto com a disseminação de informações científicas acessíveis sobre a Covid-19 e com a superação das desigualdades de gênero na Ciência.
\end{abstract}

Palavras-chave: Covid-19. Desigualdade de gênero. Passatempos.

\section{ABSTRACT}

In this paper we report the experience of the Meninas e Mulheres nas Ciências (Girls and Women in Science) Extension Project of the Universidade Federal do Paraná in disseminating technical-scientific information through ludic educational materials about Covid-19 for the great public, in Scientific Divulgation perspective. Among our educational activities, we have produced an electronic book containing word searches, crosswords and coloring pages that approach the research of female scientists

\footnotetext{
${ }^{1}$ Doutora em Educação para a Ciência. Universidade Federal do Paraná (UFPR), Curitiba, Paraná, Brasil. E-mail: camilasilveira@ufpr.br. Orcid: https://orcid.org/0000-0002-6261-1662

${ }^{2}$ Doutora em Ciências. Universidade Federal do Paraná (UFPR), Curitiba, Paraná, Brasil. E-mail: clariceamaral@ufpr.br. Orcid: https://orcid.org/ 0000-0002-4311-6113

${ }^{3}$ Doutora em Ciências. Universidade Federal do Paraná (UFPR), Curitiba, Paraná, Brasil. E-mail: glaucia.pantano@ufpr.br. Orcid: https://orcid.org/0000-0001-5868-4300

${ }^{4}$ Doutora em Física. Universidade Federal do Paraná (UFPR), Curitiba, Paraná, Brasil. E-mail: alessandra@fisica.ufpr.br. Orcid: http://orcid.org/0000-0001-7989-1878

${ }^{5}$ Doutora em Física. Universidade Federal do Paraná (UFPR), Curitiba, Paraná, Brasil. E-mail: camilla@fisica.ufpr.br. Orcid: https://orcid.org/0000-0003-1667-490X

${ }^{6}$ Doutora em Ciências. Universidade Federal do Paraná (UFPR), Curitiba, Paraná, Brasil. E-mail: tatiana.renata@ufpr.br. Orcid: https://orcid.org/0000-0003-0651-1795
} 
about coronavirus and related subjects. Data on the scope of the Project activities were collected through a documentary social research revealing the expressive reach of the book. Internet pages, websites and institutional portals of scientific societies, science museums and thematic projects shared news about the launch of the material; the authors attended dozens of remote meetings; several news and entertainment portals highlighted to the book launch and produced special articles on the MMC work related to the coronavirus. Education for Sustainable Development, from the 2030 Agenda of the United Nations, was promoted through the Learning Objectives for SDGs 3, 4, 5, 10 and 16. The results obtained highlight the project's potential and commitment to the dissemination of accessible scientific information about Covid-19 and overcoming gender inequalities in science.

Keywords: Covid-19. Gender equality. Pastime. Puzzle

\section{PANDEMIA DE COVID-19 E O PROTAGONISMO CIENTÍFICO FEMININO NA DIVULGAÇÃO CIENTÍFICA}

A pandemia de Covid-19 (COrona VIrus Disease - Doença do Coronavírus) realçou a importância da Ciência, comprometida socialmente com a minimização de riscos dos problemas contemporâneos advindos da referida doença. Isso se deve, em partes, às estratégias de comunicação pública adotadas pelos diversos meios de comunicação de massa com forte inserção e atuação de cientistas, na perspectiva da Divulgação Científica.

A Divulgação Científica (DC) é um campo de conhecimento de inserção prática e acadêmica que promove a articulação entre cientistas e instituições de pesquisa - e os resultados de seus feitos - e demais atores e setores da sociedade (ROCHA; MASSARANI, 2017). De maneira geral, ela é compreendida como o processo de comunicação pública da Ciência, Tecnologia e Inovação (CTI) para o grande público por meio de diferentes recursos e linguagens.

A importância da DC fundamenta-se no entendimento de que, geralmente, a população demanda informações sobre o papel da CTI para o desenvolvimento sustentável da humanidade (MONTILLA, 2015). Esta comunicação para o entendimento público visa garantir o direito à cidadania de modo que as pessoas tenham condições de se posicionar criticamente frente às decisões que envolvam CTI.

Moreira (2006) relaciona a divulgação e popularização da Ciência com a inclusão social, pois as noções científicas, o conhecimento dos principais resultados sobre os avanços científicos e tecnológicos, bem como os riscos e limitações, assim como os interesses em jogo, são essenciais para o exercício da cidadania plena no mundo atual. Ainda, segundo Moreira (2006), a DC se processa por meio de diversos mecanismos 
como os museus de ciências, os programas de extensão universitários, os eventos de divulgação, os meios de comunicação dentre outros.

Nessa mesma direção, Souza e Rocha (2015, p. 127) suscitam que:

O principal objetivo da Divulgação Científica (DC) é garantir o acesso da população aos conhecimentos científicos e tecnológicos, considerando a relevância dos impactos da ciência e da tecnologia na sociedade e no ambiente. Presente em jornais, revistas, rádio, TV, internet, redes sociais, livros, filmes, documentários, museus e centros de ciência, dentre outros espaços, a DC se torna cada vez mais valorizada, o que justifica a importância da problematização, ampliação e aperfeiçoamento das atividades de DC, permitindo a democratização dos conhecimentos científicos.

Em vista disso, a DC se realiza em conjunto entre os que estão na construção de novos conhecimentos, produtos ou tecnologias, e a população em geral que é diretamente influenciada por essas atividades (KASSEBOEHMER; PARRA, 2015). Assim, Caldas (2011, p. 26) explicita que:

É essencial, no processo de divulgação científica, a necessária reflexão sobre
as relações de poder que envolvem a produção científica. Não se trata,
obviamente, de demonizar os diferentes atores sociais que envolvem a política
científica do país, seja a comunidade científica, o governo, o setor produtivo,
mas garantir a polifonia das vozes, considerando o papel e o poder da mídia na
formação do imaginário social, calcado em uma aldeia global, em que tudo se
articula em teias multimídias, com informações fragmentadas, destituídas de
contexto, sem uma perspectiva histórica, que permita interligar o presente ao
passado, estabelecendo correlações para uma perspectiva futura.

Isto posto, "cabe aos divulgadores da Ciência o papel de levar até a sociedade as bases de uma cultura científica, mostrando os riscos e benefícios do conhecimento produzido pela Ciência, promovendo um intercâmbio entre cientistas e a sociedade" (CUNHA; GIORDAN, 2009, p. 7) e estarem atentos sobre a relevância da divulgação do conhecimento científico, como aponta Bueno (2010, p. 5):

A divulgação científica cumpre função primordial: democratizar o acesso ao
conhecimento científico e estabelecer condições para a chamada alfabetização
científica. Contribui, portanto, para incluir os cidadãos no debate sobre temas
especializados e que podem impactar sua vida e seu trabalho, a exemplo de
transgênicos, células tronco, mudanças climáticas, energias renováveis e
outros itens (BUENO, 2010, p. 5).

A DC realizada sobre a pandemia da doença do novo coronavírus busca alcançar a população de nosso país, no intento de provocar um certo domínio dos conhecimentos científicos e tecnológicos, justificada, também, pela ausência de uma educação científica abrangente e de qualidade nos ensinos Fundamental e Médio brasileiro (MOREIRA, 2006, p. 11). De modo a ampliar o alcance das atividades de DC, esta forma de educação deve abranger a população marginalizada e, além disso, envolver diversas instituições, 
universidades, cientistas, educadores, estudantes e o público em geral, favorecendo a inclusão social, o que, de acordo com Moreira (2006, p. 11), é um grande desafio para o Brasil, pois "por razões históricas, acumulou enorme conjunto de desigualdades sociais no tocante à distribuição da riqueza, da terra, do acesso aos bens materiais e culturais e da apropriação dos conhecimentos científicos e tecnológicos”.

Nesse processo de comunicar publicamente os avanços científicos e os impactos desses no enfrentamento da pandemia, o trabalho das mulheres cientistas veio à tona. Em fevereiro de 2020, duas cientistas brasileiras tiveram seu trabalho sobre o sequenciamento genético do novo coronavírus bastante disseminado na mídia nacional e internacional, fortalecendo a pauta feminista na Ciência. Essas pesquisadoras, Ester Sabino e Jaqueline Goes de Jesus, realizaram o grande feito, em um tempo recorde, junto a uma equipe de especialistas formada, majoritariamente, por mulheres. Uma pesquisa científica de excelência realizada por mulheres cientistas notáveis.

Ocorre, porém, que raríssimas são as ocasiões como a mencionada. As mulheres cientistas sofrem, até os tempos atuais, um cenário de sub-representação, de silenciamento, invisibilização e apagamento de seus feitos. Isso impacta na falta de repertório que a maioria das pessoas apresenta sobre trajetórias de mulheres cientistas; o desconhecimento das grandes contribuições femininas para o desenvolvimento científico e da própria humanidade; e a falta de motivação para que meninas e mulheres sigam as carreiras científicas. Além disso, reforça estereótipos, perpetua opressões, violências e discriminações de gênero que evitam o desenvolvimento sustentável e pleno de qualquer nação.

Todavia, desde que a pandemia se instaurou no Brasil, é comum ligarmos a televisão, ouvirmos rádio, lermos um jornal e nos depararmos com comentários especializados sobre a doença vindo de pesquisadoras, de cientistas e médicas. Iniciou-se um percurso de dar voz e visibilidade, ainda que não de forma intencional, a essas mulheres. Os efeitos se tornaram perceptíveis ao observarmos, comumente, essas referências sendo mencionadas em conversas rotineiras do público leigo e especializado.

As mulheres estão na linha de frente de muitos setores diretamente envolvidos com as questões da pandemia e isso precisa ficar registrado como um legado histórico importante para a nossa humanidade. Em face disso, no corrente ano de 2021, o tema central do Dia Internacional das Mulheres e Meninas na Ciência, - data instituída pela 
Unesco e ONU Mulheres desde dezembro de 2015 - foi Mulheres cientistas na linha de frente da luta contra a Covid-19. Tal marco simbólico coloca as mulheres cientistas em destaque e reconhece o valor do trabalho protagonista de muitas pesquisadoras.

Neste artigo, relatamos a experiência do Projeto de Extensão Meninas e Mulheres nas Ciências da Universidade Federal do Paraná (UFPR) em divulgar informações técnicas por meio de materiais lúdico-educativos sobre a Covid-19, na perspectiva da Divulgação Científica, para o grande público.

\section{AÇÕES EXTENSIONISTAS DE DIVULGAÇÃO CIENTÍFICA DO MENINAS E MULHERES NAS CIÊNCIAS SOBRE CORONAVÍRUS}

Na UFPR, o Projeto de Extensão Universitária Meninas e Mulheres nas Ciências (MMC), com o intuito de contribuir com a educação científica do grande público sobre os assuntos relacionados à doença do coronavírus e para valorizar o protagonismo das mulheres cientistas envolvidas nesse cenário, produziu um livro de passatempos que foi lançado em 22 de maio de 2020, em formato eletrônico e de acesso gratuitoi

O material conta com 71 páginas entre os passatempos (19 caça-palavras, 15 palavras-cruzadas, e oito desenhos para colorir), suas respostas e indicação de referências. As atividades abordam o trabalho das cientistas sobre o coronavírus e os assuntos correlatos e nelas localizam-se informações tais como: modos de contaminação pelo coronavírus SARS-CoV-2; estrutura do vírus; caracterização e identificação dos vírus do tipo coronavírus; significado da abreviação Covid-19; importância do sequenciamento genético do novo coronavírus; uso do álcool em gel; produção de medicamentos e de vacinas; ação das máscaras faciais; protocolos de saúde pública; eficiência da higienização das mãos; comportamento social; modelagem matemática para previsão do cenário de contágio da doença; papel das instituições de pesquisa, com destaque para a Fiocruz; dentre outras.

Ele foi escrito, produzido e diagramado por seis professoras doutoras do Setor de Ciências Exatas da UFPR, sendo quatro do Departamento de Química: Camila Silveira Clarice Amaral, Glaucia Pantano e Tatiana Renata Gomes Simões; e duas do Departamento de Física: Alessandra Souza Barbosa e Camilla Karla Oliveira. As 
ilustrações digitais que constam na obra são do estudante de Licenciatura em Física Marcelo Jean Machado.

A fim de ilustrar o formato do conteúdo disseminado, na Figura 1 há a reprodução da capa do livro, de um caça-palavras da obra intitulado Qual a importância do álcool em gel? e um desenho para colorir da virologista escocesa June Almeida.

Figura 1 - Reprodução da capa do Livro, de um caça-palavras e um desenho para colorir contidos nele.

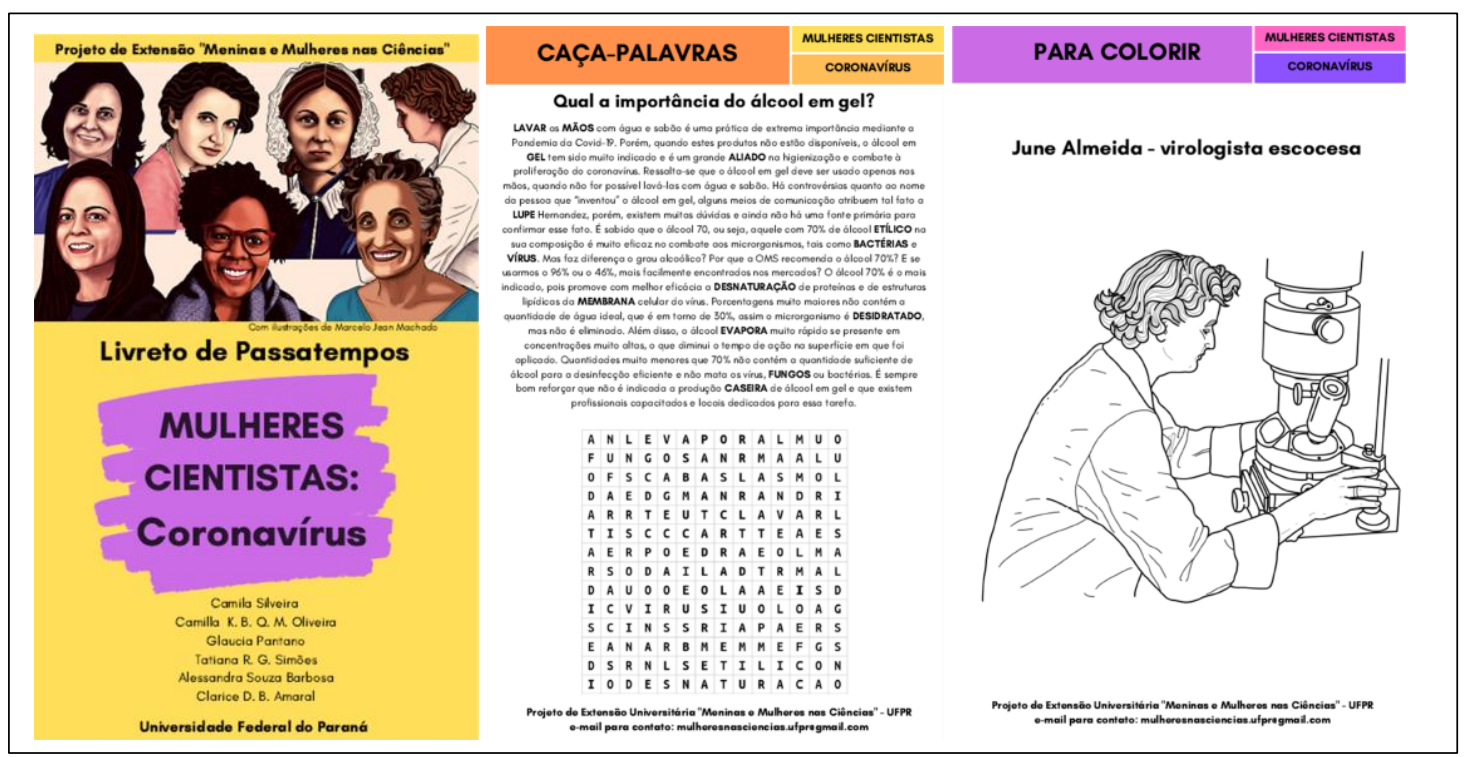

Fonte: Meninas e Mulheres nas Ciências, UFPR, 2020.

O MMC tem um forte compromisso assumido com os Objetivos de Desenvolvimento Sustentável (ODS) da Agenda 2030 da Organização das Nações Unidas (ONU). No livro, a abordagem para a sustentabilidade é ressaltada para os ODS: 3 - Bemestar e Saúde, 4 - Educação de Qualidade, 5 - Igualdade de Gênero, 10 - Redução das Desigualdades e 16 - Paz, Justiça e Instituições Eficazes. Ainda, por ser um projeto de extensão universitária na área da Educação, busca promover os objetivos de aprendizagem nos campos cognitivo, socioemocional e comportamental para cada um dos ODS mencionados, focando em: 3 - Assegurar uma vida saudável e promover o bemestar para todos, em todas as idades; 4 - Assegurar a educação inclusiva e equitativa de qualidade, e promover oportunidades de aprendizagem ao longo da vida para todos; 5 Alcançar a igualdade de gênero e empoderar todas as mulheres e meninas; 10 - Reduzir a desigualdade dentro dos países e entre eles; e 16 - Promover sociedades pacíficas e inclusivas para o desenvolvimento sustentável, proporcionar o acesso à justiça para todos 
e construir instituições eficazes, responsáveis e inclusivas em todos os níveis (UNESCO, 2017).

As atividades divulgadas junto ao público possuem potencialidades para comunicar temáticas científicas, bem como o papel protagonista das mulheres na produção desses conhecimentos ao longo da história e de liderança no panorama atual da pandemia de Covid-19. Concomitantemente, buscam inspirar e empoderar meninas e mulheres por meio das histórias de vida e dos feitos das cientistas, além de promover justiça social, educação de qualidade, bem-estar e equidade de gênero.

No livro, os passatempos valorizam os feitos das cientistas Ana Néri, Bruna Sabagh, Celia Landmann, Daniela Trivela, Deborah Carvalho Malta, Ester Sabino, Florence Nightingale, Jaqueline Goes de Jesus, June Almeida, Kizzmekia Corbett, Lupe Hernandez, Marilisa Barros, Mayana Zatz, Nísia Trindade de Lima, Rosalind Franklin, Sara del Valle e Sonia Raboni. Além de colaborarem para que elas sejam (re)conhecidas pelo público quando mencionadas em outros espaços - ampliação de repertório feminino -, e para o entendimento dos conceitos técnicos envolvidos na situação de pandemia ampliação de repertório científico.

Juntamente com o lançamento do livro de passatempos e do Blog do Projeto foram criados perfis nas redes sociais do MMC, no Facebook e no Instagram, sob o domínio @mulheresnasciencias.ufpr. As redes sociais foram adotadas como canais de DC para atingir diferentes perfis de públicos.

Após o lançamento do livro de passatempos, o MMC passou a disponibilizar jogos e outras atividades lúdicas em seu Blogii buscando ampliar e diversificar o tipo de acesso e de público. Sobre a série temática das Mulheres Cientistas do Coronavírus a equipe converteu alguns caça-palavras e palavras-cruzadas do Livro para o formato online, para que as pessoas pudessem jogar diretamente pela internet e criou passatempos como desenhos bônus para colorir, um jogo da memória e quebra-cabeças (nível fácil e difícil) das cientistas ilustradas na obra.

\section{O ALCANCE E OS RESUltados DAS AÇÕES DE DIVUlgaÇÃo CIENTÍFICA DO MMC SOBRE CORONAVÍRUS}


Os materiais desenvolvidos pelo MMC sobre coronavírus tiveram expressivo alcance desde o lançamento do primeiro produto, que foi o livro de passatempos. Nesta seção, apresentaremos resultados que evidenciam o papel do Projeto na divulgação de temas e conceitos científicos sobre a Covid-19, com valorização do trabalho realizado por mulheres cientistas. Pelo fato de a pandemia ter potencializado, a atuação de cientistas nas redes sociais e na internet, de modo mais abrangente, o MMC se fez presente na popularização das informações oficiais de muitos setores da sociedade, por meio das mídias eletrônicas, mas também dos meios de comunicação tradicionais da grande massa.

Os dados expostos foram constituídos por meio de pesquisa social (MYNAIO, 2011) documental sobre os registros localizados nas mídias referentes ao Projeto de Extensão, fazendo uso de descritores combinados entre si, tais como: mulheres cientistas; coronavírus, passatempos; UFPR; livro de passatempos; Covid-19; professoras da UFPR.

Páginas de internet, sites e portais institucionais de sociedades científicas, museus de ciências e projetos temáticos compartilharam notícias sobre o lançamento do material, tal como a SBPC - Sociedade Brasileira para o Progresso da Ciência (Professoras da UFPR lançam livro de passatempos sobre mulheres cientistas no combate ao coronavírus, 26 de maio de 2020); SBF - Sociedade Brasileira de Física (Livro sobre mulheres cientistas no combate ao coronavírus, 28 de maio de 2020); SBQ - Sociedade Brasileira de Química (Professoras da UFPR lançam livro de passatempos sobre mulheres cientistas no combate ao coronavírus; baixe gratuitamente, 05 de junho de 2020); Espaço Ciência Viva (Livro Mulheres Cientistas: Coronavírus, 25 de maio de 2020); e Para Mulheres na Ciência - L'Oréal Brasil (Projeto da UFPR lança livro de atividades sobre mulheres cientistas no combate a Covid-19, 09 de junho de 2020).

Esses locais colaboraram para que o Livro tivesse um espaço de legitimação pela comunicação científica, que reconheceu a relevância do material para a educação científica da população e a temática central adotada na produção.

As professoras da equipe participaram (virtualmente) de dezenas de eventos, incluindo seminários, simpósios, palestras, oficinas, em diferentes localidades brasileiras, para falarem especificamente sobre o livro das Mulheres Cientistas do Coronavírus. Como exemplo, destacamos a Mesa Redonda na $2^{\text {a }}$ Semana Estadual de Ciência, Tecnologia, Inovação e Desenvolvimento promovida pela Secretaria de Estado de Ciência, Tecnologia e Educação Profissional e Tecnológica (Sectet) do estado do Pará, 
realizada no período de 23 a 26 de junho de 2020, com o tema Em tempos de pandemia. Na Figura 2, é apresentado o cartaz de divulgação sobre a referida Mesa.

Figura 2 - Cartaz de divulgação da mesa redonda para a Sectet, Pará, 2020.

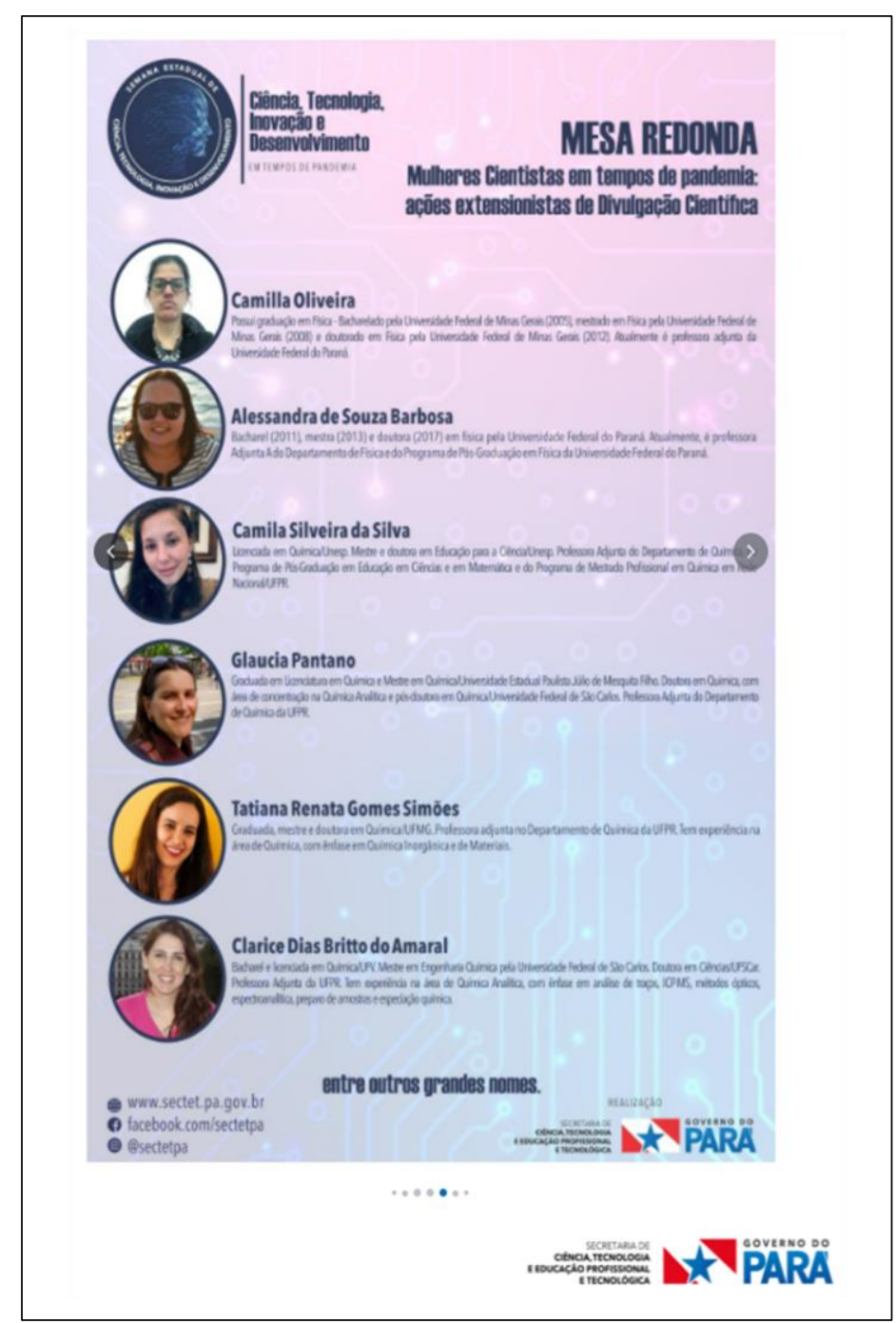

Fonte: Sectet, Pará, 2020.

Na ocasião desta Mesa, as professoras falaram sobre Mulheres Cientistas em tempos de pandemia: ações extensionistas de Divulgação Científica e o público participante interagiu de forma bastante entusiasmada em conhecer detalhes sobre o livro publicado e as demais atividades relacionadas.

Inúmeras fanpages do Facebook redigiram posts específicos para divulgar o livro ou repostaram as postagens do perfil oficial do MMC e da própria UFPR. O Projeto de Extensão Meninas na Ciência, da Universidade Federal do Rio Grande do Sul, fez a 
divulgação em sua fanpage compartilhando o link da notícia do lançamento do livro do Portal da UFPR e, somente por lá, foram mais de 430 compartilhamentos do post conforme Figura 3a. O post feito pela fanpage da UFPR teve mais de 700 compartilhamentos diretos de sua postagem (Figura 3b).

Figura 3 - Cópias das telas das postagens das fanpages do Meninas na Ciência - UFRGS, e da UFPR, divulgando o livro.

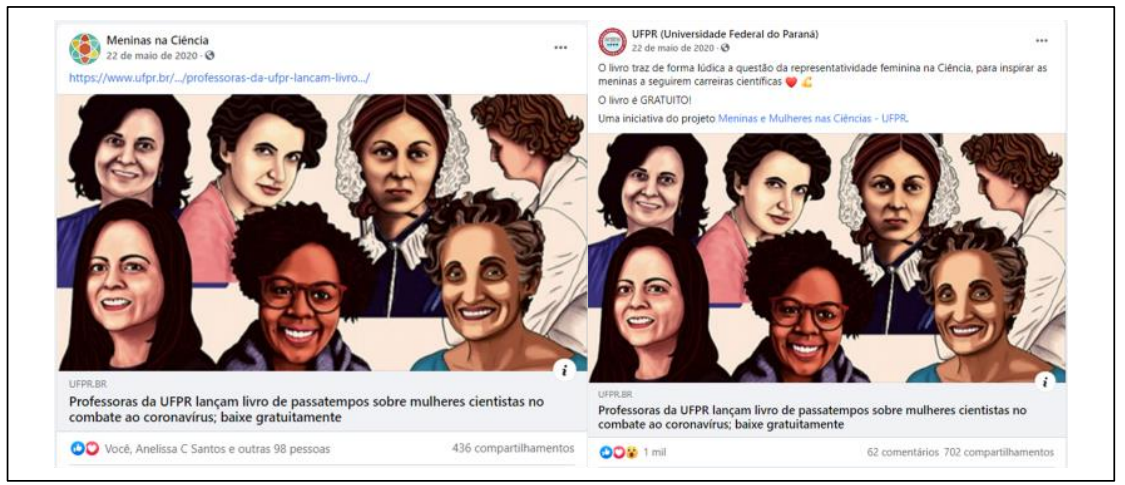

Fonte: Meninas na Ciência, UFRGS; UFPR, 2020.

O mesmo ocorreu com o Instagram, a exemplo do perfil do Projeto Celina, vinculado ao jornal O Globo, do Rio de Janeiro, que fez uma postagem a partir de uma entrevista realizada com a coordenadora do Projeto (Figura 4).

Figura 4 - Reprodução do post do Instagram do Projeto Celina sobre o livro.

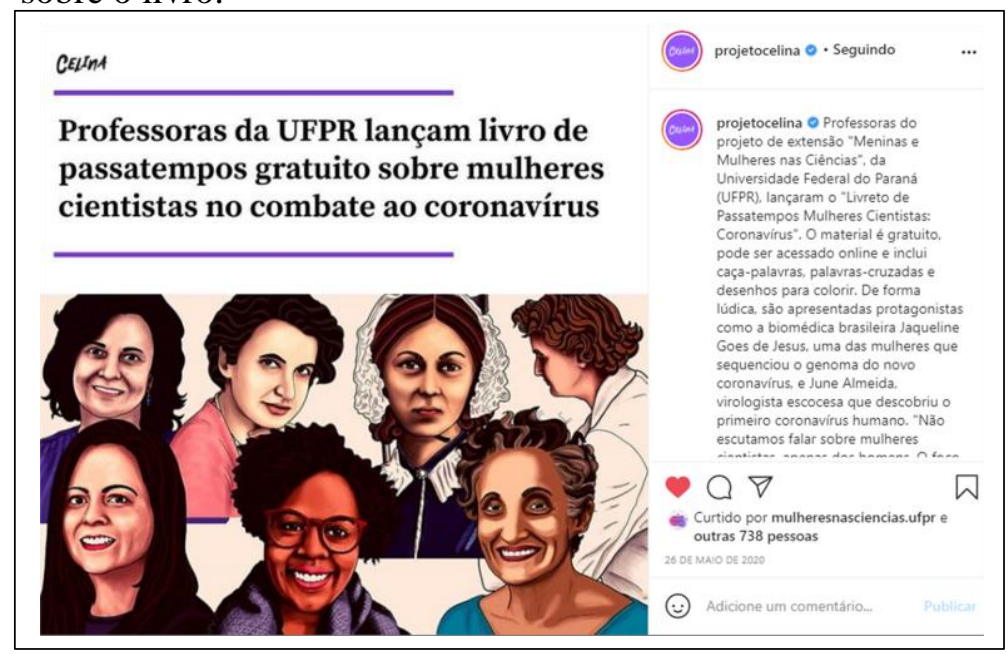

Fonte: Projeto Celina, O Globo, 2020.

A postagem do Celina teve grande abrangência e engajamento na referida rede social, com comentários do público enaltecendo a iniciativa e indicando o interesse em acessar e baixar o arquivo digital do livro. 
A presença constante na mídia também é outro resultado desse alcance expressivo que as cientistas da equipe tiveram e que oportunizaram canais de diálogo com a população brasileira. As professoras falaram em canais de televisão, rádio, podcast e jornais. Uma amostra foi a participação no Programa Bom Dia Sábado, da emissora de televisão RPC, afiliada da Rede Globo. O programa exibido no dia 30 de maio de 2020 destaca o livro, as informações científicas e as mulheres retratadas na obra. A Figura 5 reproduz a cópia da tela do vídeo da notícia.

Figura 5 - Cópia de tela da notícia exibida na RPC - Bom dia Sábado.

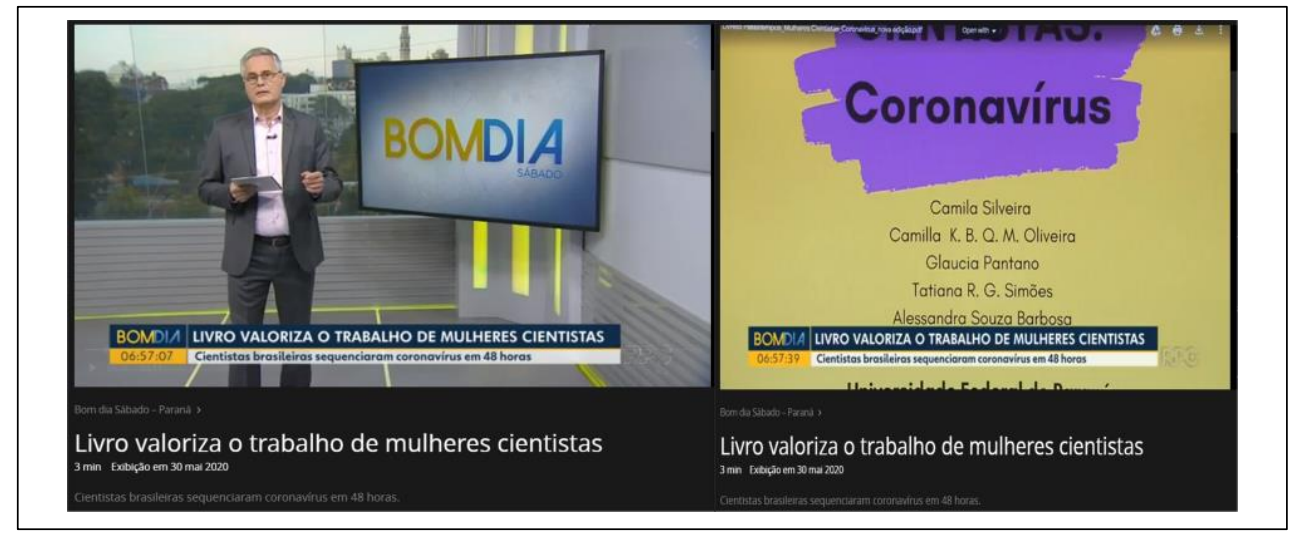

Fonte: RPC, 2020.

O jornal impresso Folha de Londrina produziu uma edição especial de final de semana sobre o livro com quatro páginas inteiras. A versão digital reproduzida na Figura 6 ilustra o formato da matéria.

Figura 6 - Reprodução da matéria especial produzida pela Folha de Londrina.

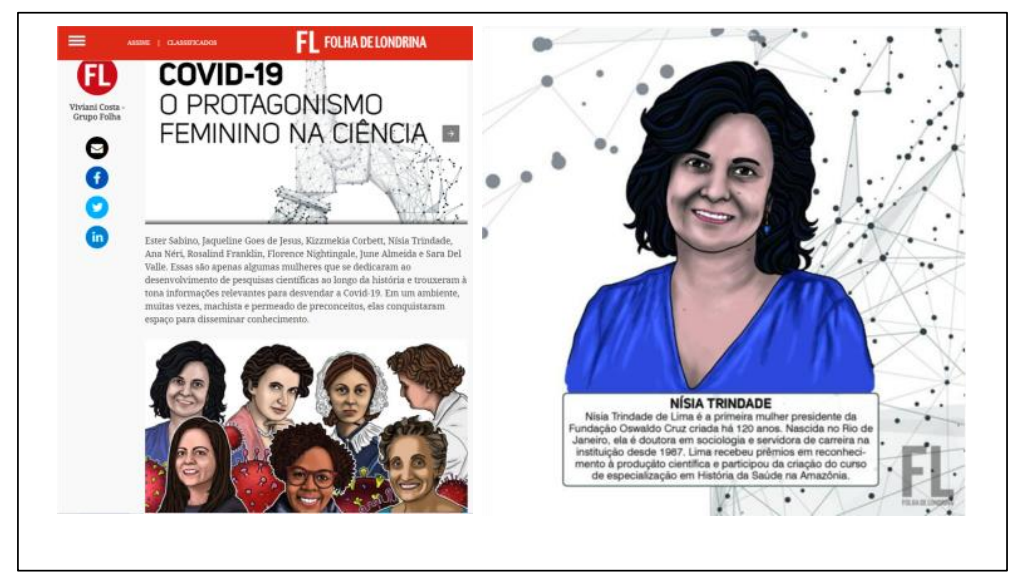

Fonte: Folha de Londrina, 2020. 
Essa matéria especial de final de semana da Folha de Londrina conta com trechos da entrevista realizada com professoras da equipe, infográficos elaborados a partir das ilustrações do livro, dados sobre a situação das mulheres cientistas em termos de subrepresentação e ao mesmo tempo evidencia o protagonismo desempenhado na pandemia da Covid-19. Ainda, realça o compromisso da equipe do MMC com a Agenda 2030 da ONU e seus respectivos ODS e dialoga com outras iniciativas de empoderamento feminino. Ganharam destaques os gráficos das cientistas Rosalind Franklin, Sara Del Vale, Florence Nightingale, Ester Sabino, Jaqueline Goes de Jesus, June Almeida e Nísia Trindade, o que indica o empenho da comunicação em detalhar o conteúdo do livro e torná-lo atrativo para as leitoras e os leitores.

Diversos portais de notícias e entretenimento avultaram o livro e produziram matérias especiais sobre o trabalho do MMC em relação ao Coronavírus. Foram casos como os do UOL, no canal Universa - dedicado a notícias sobre universidades -, que publicou em 06 de julho de 2020, a matéria em Mulheres Inspiradoras, sob o título Coronavírus e mulheres cientistas viram tema de livro de passatempos (Figura 7).

Figura 7 - Reprodução da matéria especial produzida pelo Universa, UOL.

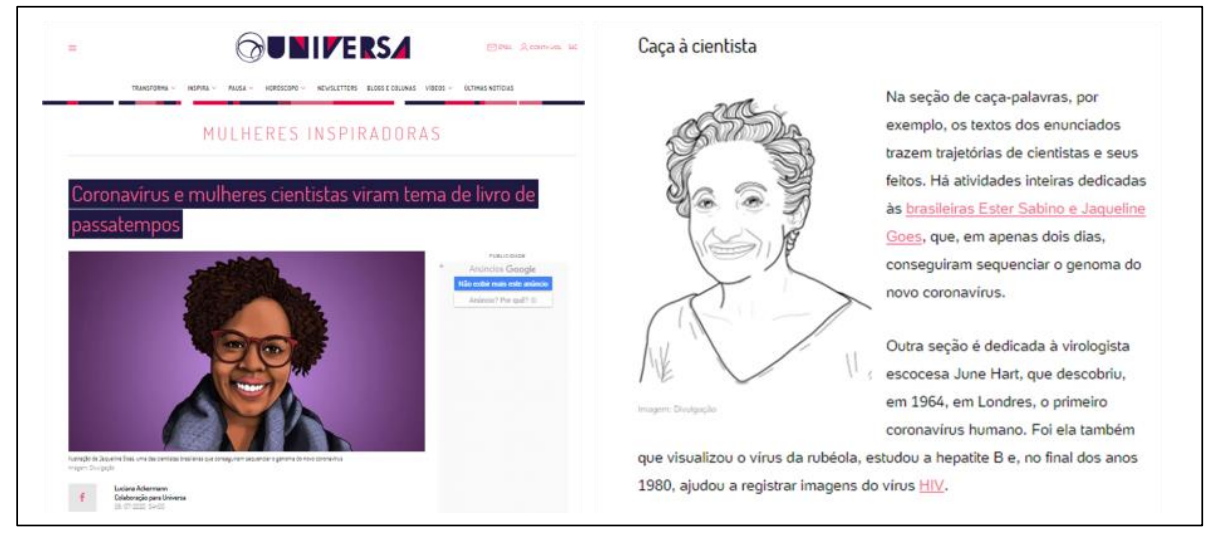

Fonte: UOL, Universa, 2020.

A matéria do UOL apresenta detalhes sobre os passatempos, com reproduções das ilustrações de algumas cientistas, inserindo falas extraídas da entrevista realizada com a coordenadora do Projeto e abordando o machismo estrutural na Ciência, em outra seção da notícia. Observa-se um trabalho de pesquisa sobre o livro que demonstra o interesse em popularizar e cativar o público sobre o conteúdo, reforçando que o material traz definições e conceitos de "um jeito simples e claro". 
Jornais digitais como o Nexo Jornal também fizeram textos sobre o material (O livro de passatempos sobre as cientistas que estudam o coronavírus, em 10 de julho de 2020) conforme consta na Figura 8.

Figura 8 - Reprodução da matéria do Nexo Jornal sobre o livro.

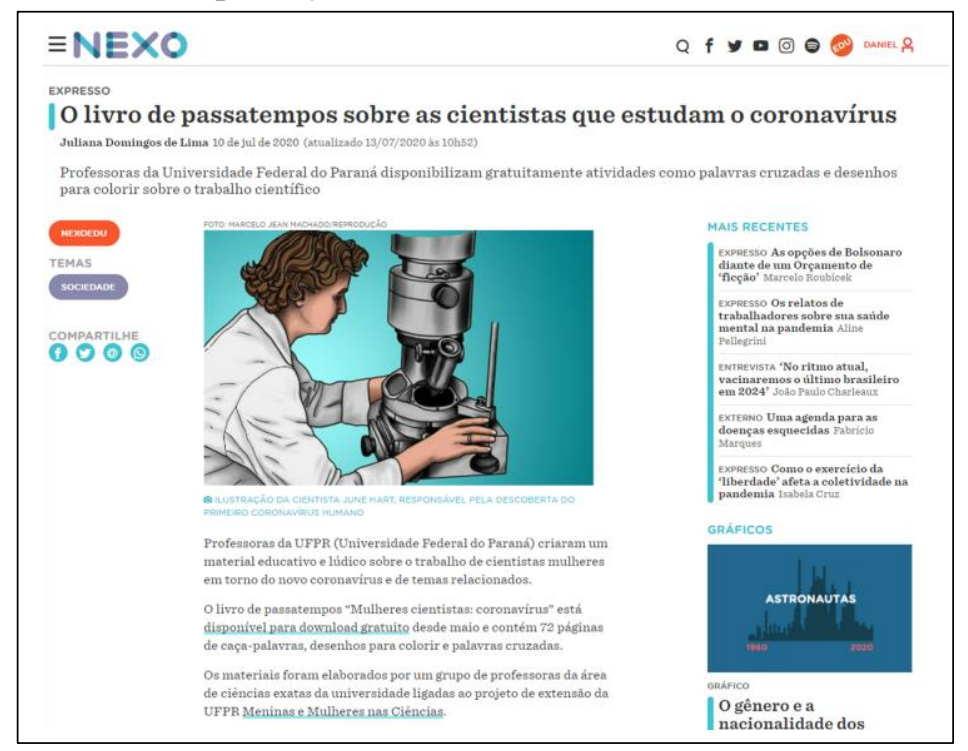

Fonte: Nexo Jornal, 2020.

Além de reproduzir a imagem de June Hart que consta no livro, legendando como a "responsável pela descoberta do primeiro coronavírus humano", o texto realça o caráter lúdico e educativo do material produzido, marca a autoria e o vínculo institucional do MMC. Além disso, há uma seção intitulada 3 cientistas que estão no livreto, que informa sobre: June Hart, Ester Sabino e Kizzmekia Corbett.

As rádios locais, regionais e nacionais abriram espaços para sonoras e entrevistas ao vivo para que as autoras falassem sobre o livro a exemplo da CBN Curitiba e Rádio Unesp, conforme podem ser vistos nas reproduções da Figura 9.

Figura 9 - Cópias de telas da Rádio CBN - Curitiba e da Rádio Unesp divulgando o livro.

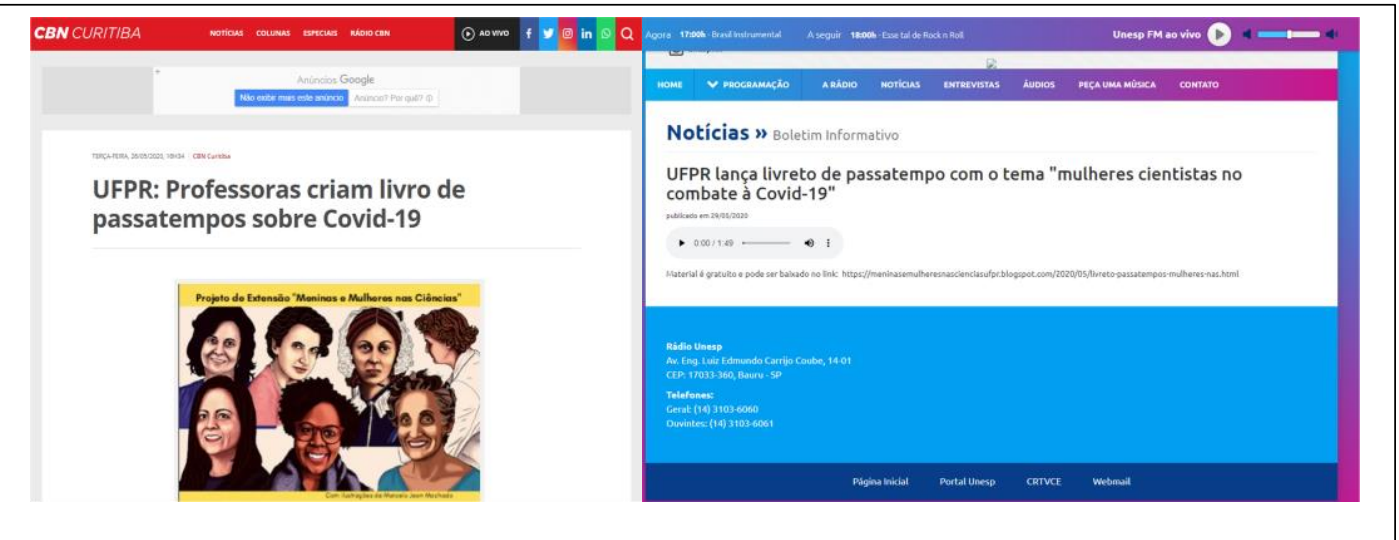


Fonte: Rádio CBN - Curitiba; Rádio Unesp, 2020.

As conversas nas rádios giraram em torno da temática do livro, sobre as cientistas retratadas, o processo de elaboração do material, o objetivo do $\mathrm{MMC}$, e os temas científicos explorados nos passatempos.

A adoção do livro, em parte ou no todo, bem como os demais passatempos associados à obra constituíram materiais didáticos em redes de educação municipais, estaduais, federais e privadas de todos os níveis de ensino. Um caso está representado na Figura 10, na qual consta a reprodução do Material de Complementação Escolar da Prefeitura da cidade do Rio de Janeiro/RJ referente ao $1^{\circ}$ Semestre de 2020.

Figura 10 - Reprodução do material didático da Prefeitura Municipal do Rio de Janeiro.

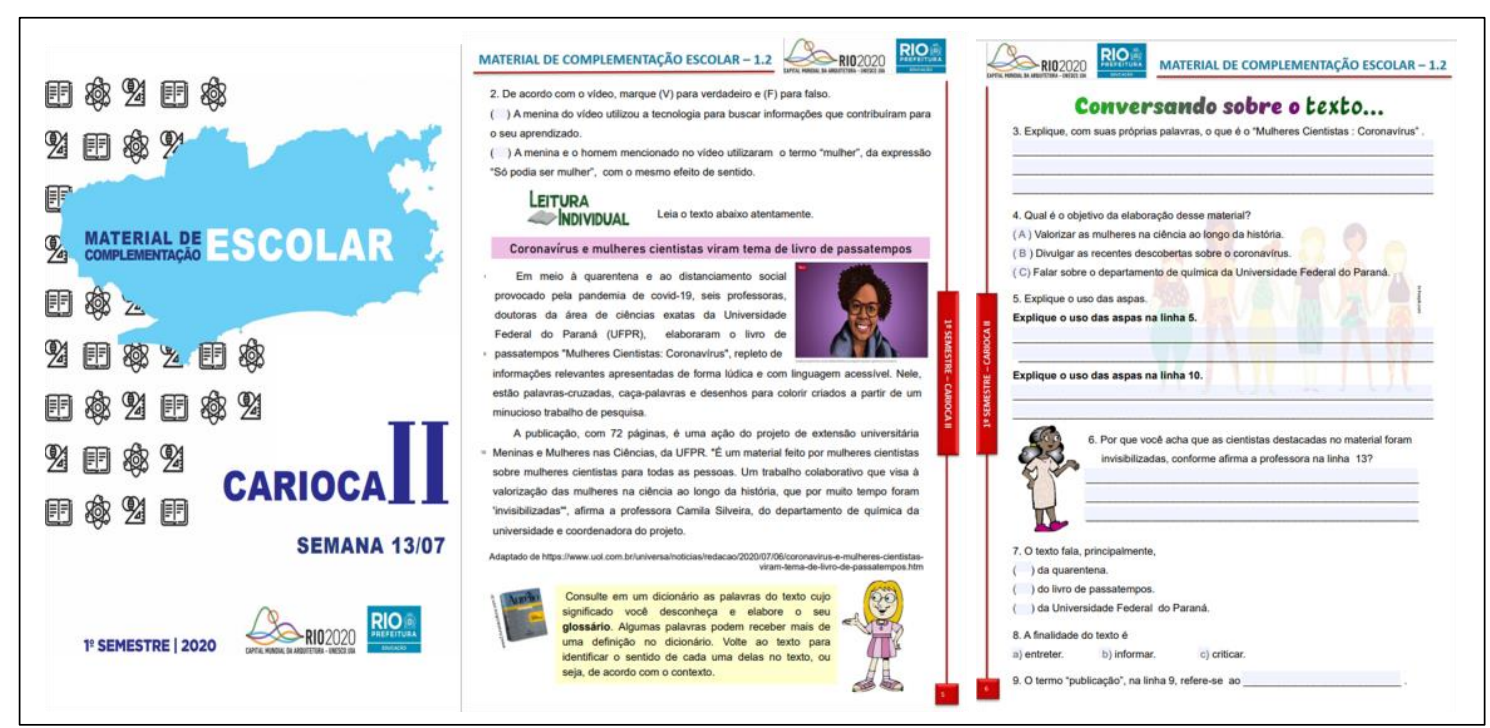

Fonte: Secretaria Municipal de Educação da cidade do Rio de Janeiro, 2020.

Casos semelhantes ao anterior são apresentados na Figura 11 onde constam, à esquerda, a cópia de uma atividade escolar da EMEF Lourdes Fontoura da Silva, na cidade de Sapucaia do Sul, no Rio Grande do Sul; e, à direita, o print da tela do Canal do YouTube da TV Escola Curitiba da aula de Ciências exibida no dia 09 de julho de 2020 e que reuniu atividades do MMC indicadas aos alunos e alunas. 
Figura 11 - Reprodução de atividades escolares com passatempos do MMC sobre

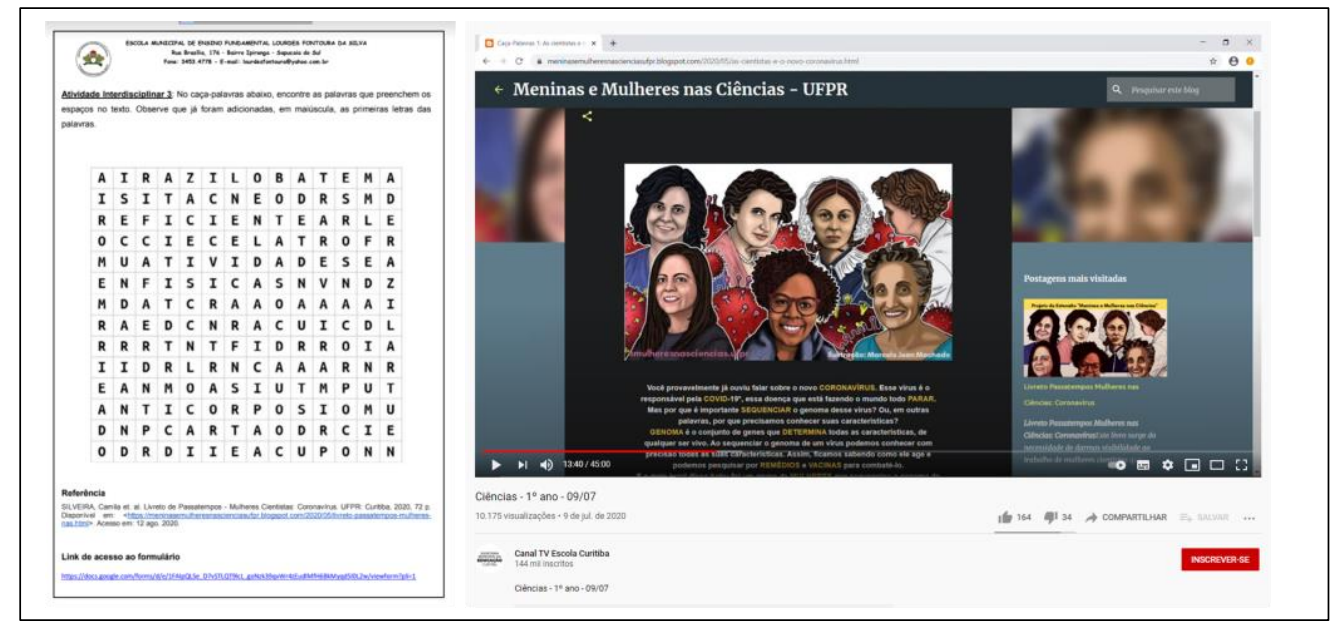

Fonte: EMEF Lourdes Fontoura da Silva; Canal do YouTube da TV Escola Curitiba, 2020.

Os dados expostos ao longo desta seção do texto revelam que as estratégias de inclusão social buscaram atingir diversas parcelas da população que se encontram excluídas do processo de conhecimento científico básico (MOREIRA, 2006). A ampliação do alcance dessas atividades de DC procuraram abranger a população marginalizada pelas vias da democratização da apropriação dos conhecimentos científicos e tecnológicos.

De acordo com Loureiro (2003, p. 91), a DC “constitui-se no emprego de técnicas de recodificação de linguagem da informação científica e tecnológica objetivando atingir o público em geral e utilizando diferentes meios de comunicação de massa", possibilitando que a população perceba que a Ciência é um processo para a construção de conhecimentos, inovações e tecnologias que estão diretamente relacionados às demandas da sociedade contemporânea.

Analisando os dados sob a ótica da Educação para o Desenvolvimento Sustentável, tomando os objetivos de aprendizagens ancorados em três campos: i) cognitivo “compreende conhecimentos e habilidades de pensamento necessários para compreender melhor os ODS e os desafios para alcançá-los" -; ii) socioemocional - “inclui habilidades sociais que permitem que os educandos colaborem, negociem e se comuniquem para promover os ODS, bem como habilidades de autorreflexão, valores, atitudes e motivações que permitem que os educandos se desenvolvam" -; e iii) comportamental - "descreve competências de ação" (UNESCO, 2017, p. 11), exemplificativamente, apontamos que para o ODS 3 - Saúde e Bem-estar -, o livreto e as atividades provenientes dele, podem 
ser considerados como estratégias de aprendizagem recomendadas pela UNESCO (2017) por tratarem de endemias e epidemias (ARAÚJO et al., 2021, no prelo).

A aprendizagem cognitiva para esse ODS ocorreu, pois identificamos que as atividades favoreceram a divulgação de protocolos de saúde pública para minimização do contágio da Covid-19, pelos conceitos de imunidade e higienização que são abordados nos passatempos; e destacaram a atuação protagonista de Florence Nightingale em relação à higienização das mãos como uma prática que reduz contaminações. O livro ressalta fatos históricos e situações contemporâneas sobre os modos de transmissão de doenças que provocam síndromes respiratórias, tais como a Covid-19 (ARAÚJO et al., 2021, no prelo).

A aprendizagem socioemocional do ODS 3 é oportunizada por meio da divulgação sobre os sintomas mais frequentes da doença e os casos de agravamento, o que pode orientar as pessoas sobre como proceder em relação à busca por orientação médica especializada. O comportamento social é fortemente retratado na obra (ARAÚJO et al., 2021, no prelo).

A aprendizagem comportamental foi possibilitada pelo incentivo à vacinação, por mostrar e explicar meios para a promoção da saúde, divulgar o trabalho das instituições de pesquisa e por sensibilizar as pessoas sobre o desenvolvimento científico protagonizado pelas mulheres cientistas (ARAÚJO et al., 2021, no prelo).

Os três campos de aprendizagem foram contemplados para os demais ODS abordados nas atividades do livro sobre as Mulheres Cientistas e Coronavírus: 4, 5, 10 e 16. Isso revela as potencialidades educativas do material e das estratégias adotadas pela equipe do MMC para a promoção da DC comprometida com as demandas sociais, em particular, com a disseminação de informações científicas acessíveis sobre a Covid-19 e com a superação da desigualdade de gênero na Ciência.

\section{CONSIDERAÇÕES FINAIS}

O grande alcance das ações de divulgação científica do Meninas e Mulheres nas Ciências sinaliza que a abordagem escolhida para tratar dos assuntos sobre a pandemia foi atrativa e acessível ao grande público. O formato inovador, marcado pelos 
passatempos, contribuiu para que a dimensão lúdica ganhasse valor associada à dimensão educativa.

A educação científica é fundamental para o enfrentamento da pandemia de Covid19, pois a população brasileira carece dessa formação e o MMC está cumprindo seu papel social, como um Projeto de Extensão Universitária, produzindo e distribuindo conteúdos de qualidade, mas com uma linguagem acessível, que orientaram e orientarão processos educativos formais, não formais e informais.

A valorização e o reconhecimento do protagonismo feminino no enfrentamento da doença do novo coronavírus, por meio da pesquisa científica e liderança em outros campos, colabora para a redução das injustiças históricas que as mulheres vivenciaram. Além disso, a inserção das pesquisadoras e divulgadoras da equipe nas várias mídias se associa a esse último aspecto, sendo um meio de reafirmação de novos exemplos de pessoas que fazem Ciência, podendo modificar o imaginário coletivo sobre o estereótipo de cientista, por muito tempo vigente.

\section{AGRADECIMENTOS}

As autoras agradecem a todas as pessoas integrantes da equipe do MMC; à PROEC/UFPR; ao Setor de Ciências Exatas/UFPR; ao DQUI/UFPR; ao DFIS/UFPR; ao CNPq, à Capes; à Fundação Araucária; e a todas as pessoas e instituições parceiras do Projeto.

\section{NOTAS}

\footnotetext{
${ }^{\mathrm{i}}$ Link para acesso ao arquivo do Livro: Livreto Passatempos Mulheres Cientistas: Coronavírus (meninasemulheresnascienciasufpr.blogspot.com)

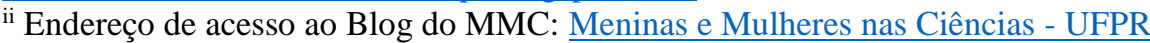
(meninasemulheresnascienciasufpr.blogspot.com)
}

\section{REFERÊNCIAS}

ARAÚJO, Iolanda Ponzetta; FERREIRA, Gabriela; KUNDLATSCH, Aline; D'ORNELAS, Alana; ANJOS, Carolina Costa dos; SILVEIRA, Camila. Analisando o livro de passatempos "Mulheres Cientistas: Coronavírus" a partir dos objetivos da 
Educação para o Desenvolvimento Sustentável. Revista Extensão Tecnológica, Blumenau, v. x, n. x, p. Xx-xx, 2021. No prelo.

BERTOLDO, Raquel Roberta; GIORDAN, Marcelo A Divulgação Científica como um produto da Indústria Cultural. In: ENCONTRO NACIONAL DE PESQUISA EM EDUCAÇÃO EM CIÊNCIAS, 11, 2017, Florianópolis. Anais... Rio de Janeiro: Associação Brasileira de Pesquisa em Educação em Ciências (ABRAPEC), 2017, p. 19.

BUENO, Wilson Costa. Comunicação Científica e Divulgação Científica: aproximações e rupturas conceituais. Informação \& Informação, v. 15, n. esp., p. 1-12, 2010.

CALDAS, Graça. Mídia e políticas públicas para a comunicação da ciência. In:

Diálogos entre ciência e divulgação científica: leituras contemporâneas. Salvador: EDUFBA, 2011, pp. 19-36.

CUNHA, Marcia Borin; GIORDAN, Marcelo. A divulgação científica como um gênero de discurso: implicações na sala de aula. In: ENCONTRO NACIONAL DE PESQUISA EM EDUCAÇÃ̃O EM DE CIÊNCIAS, Atas..., 7, ABRAPEC: Florianópolis, 2009.

GERMANO, Marcelo Gomes; KULESZA, Wojciech Andrzej. Popularização da ciência: uma revisão conceitual. Caderno Brasileiro de Ensino de Física, Florianópolis, v. 24, n. 1, p. 7-25, 2007.

GUERRA, Paula. Da exclusão social à inclusão social: eixos de uma mudança paradigmática. Revista Angolana de Sociologia. v. 10, p. 91-110, 2012.

KASSEBOEHMER, Ana Cláudia; PARRA, Kenia Naara. Debates sobre a divulgação científica da Química no Brasil. In: CORRÊA, Thiago Henrique Barnabé; PÉREZ, Leonardo Fabio Martinez; MATHARAN, Gabriel Augusto. O Ensino de Química em Diálogo. Curitiba: CRV, 2015. p. 11-34.

MONTILLA, Gloria Iraima Mogollón. Discurso de divulgación cientifica y tecnológica: de la definición al análisis crítico. Revista de la Faculdad de Ingeniería U. C. V., v.30, n.1, p.15-26, 2015.

MORA, María del Carmo Sánchez, NESTOR, Alba Patricia Macías. El papel de la comunicación pública de la ciencia sobre la cultura científica: acercamientos a su evaluación. Revista Eureka sobre Ensenãnza y Divulgación de las Ciências, n. 16, v. $1,1103,2019$.

MOREIRA, Ildeu de Castro. A inclusão social e a popularização da ciência e tecnologia no Brasil. Inclusão Social, v. 1, n. 2, p. 11-16, 2006.

MYNAIO, Maria Cecília de Souza. Desafio da Pesquisa Social. In: MYNAIO, M. C. S. Pesquisa Social: teoria, método e criatividade. 30 ed. Petrópolis, RJ: Vozes, p. 09- 29, 2011. 
UNESCO - Organização das Nações Unidas. Educação para os Objetivos do Desenvolvimento Sustentável: objetivos de aprendizagem. Brasília: UNESCO, 2017. $62 \mathrm{p}$.

ROCHA, Mariana; MASSARANI, Luisa. Panorama general de la investigación en divulgación de la ciencia en América Latina. In: Aproximaciones a la investigación en divulgación de la ciencia en América Latina a partir de sus artículos académicos. Rio de Janeiro: Fiocruz, 208 p., 2017.

SOUZA, Pedro Henrique Ribeiro; ROCHA, Marcelo Borges. Caracterização dos textos de divulgação científica inseridos em livros didáticos de biologia. Investigações em Ensino de Ciências, v. 20, n. 2, p. 126-137, 2015.

Recebido em: 20 de julho de 2018.

Aceito em: 15 de abril de 2019. 